\title{
Olfactory Aversive Conditioning during Sleep Reduces Cigarette-Smoking Behavior
}

\author{
Anat Arzi, Yael Holtzman, Perry Samnon, Neetai Eshel, Edo Harel, and Noam Sobel \\ Department of Neurobiology, Weizmann Institute of Science, Rehovot, 7610001 Israel
}

Recent findings suggest that novel associations can be learned during sleep. However, whether associative learning during sleep can alter later waking behavior and whether such behavioral changes last for minutes, hours, or days remain unknown. We tested the hypothesis that olfactory aversive conditioning during sleep will alter cigarette-smoking behavior during ensuing wakefulness. A total of 66 human subjects wishing to quit smoking participated in the study ( 23 females; mean age, $28.7 \pm 5.2$ years). Subjects completed a daily smoking diary detailing the number of cigarettes smoked during $7 \mathrm{~d}$ before and following a $1 \mathrm{~d}$ or night protocol of conditioning between cigarette odor and profoundly unpleasant odors. We observed significant reductions in the number of cigarettes smoked following olfactory aversive conditioning during stage 2 and rapid eye movement (REM) sleep but not following aversive conditioning during wakefulness $(p<0.05)$. Moreover, the reduction in smoking following aversive conditioning during stage $2(34.4 \pm 30.1 \%)$ was greater and longer lasting compared with the reduction following aversive conditioning during REM $(11.9 \pm 19.2 \%, p<0.05)$. Finally, the reduction in smoking following aversive conditioning during sleep was significantly greater than in two separate control sleep experiments that tested aversive odors alone and the effects of cigarette odors and aversive odors without pairing. To conclude, a single night of olfactory aversive conditioning during sleep significantly reduced cigarette-smoking behavior in a sleep stage-dependent manner, and this effect persisted for several days.

Key words: aversive conditioning; olfaction; sleep

\section{Introduction}

Sleep is highly beneficial for learning and memory (Born et al., 2006; Dudai, 2012; Stickgold and Walker, 2013). Consolidation and reactivation of memories during sleep have been observed across a wide range of modalities and learning forms (Walker and Stickgold, 2006; Diekelmann and Born, 2010; Spoormaker et al., 2013; Ackermann and Rasch, 2014; Landmann et al., 2014). Moreover, recent studies have implied not only modification of previously acquired memories, but also implicit acquisition of entirely new associations during sleep (Arzi et al., 2012; Hauner et al., 2013). These new associations can drive altered physiological and neuronal responses during the same night of sleep and immediately upon ensuing wakefulness (Arzi et al., 2012; Hauner et al., 2013), but whether such sleep-learning can drive long-term behavioral modifications remains unclear.

Received June 5, 2014; revised Sept. 22, 2014; accepted Sept. 26, 2014.

Author contributions: A.A., E.H., and N.S. designed research; A.A., Y.H., P.S., and N.E. performed research; A.A., Y.H., P.S., N.E., and N.S. analyzed data; A.A. and N.S. wrote the paper.

This work was supported by a grant from the Lulu P. \& David J. Levidow Fund for Alzheimer's Disease and Neuroscience Research. Additional funding came from the James S. McDonnell Foundation and from the Israeli Center for Excellence in Cognitive Science.

The Weizmann Office for Technology Licensing is currently deliberating whether to file for a patent regarding a treatment for addiction based on the currently described results. The authors declare no other competing financial interests.

Correspondence should be addressed to Anat Arzi, Department of Neurobiology, Weizmann Institute of Science, Rehovot, 7610001, Israel. E-mail: Anat.arzi@gmail.com.

DOI:10.1523/JNEUROSCI.2291-14.2014

Copyright $\odot 2014$ the authors $\quad 0270-6474 / 14 / 3315382-12 \$ 15.00 / 0$
To test whether implicit associative learning during sleep can alter long-term ensuing behavior, we applied olfactory aversive conditioning to sleeping smokers. We paired between the smell of cigarettes and aversive odors during sleep, and then followed participants' smoking behavior over 7 ensuing days. This paradigm is particularly attractive for the study of behavioral changes following sleep-learning for several reasons. First, cigarette smoking provides a recurring behavior that we can monitor over time. Second, unlike the wake-inducing powers of aversive sounds (Thiessen, 1978; Horne et al., 1994; Carter et al., 2002) or aversive airborne chemicals that stimulate the trigeminal nerve (Carskadon and Herz, 2004; Stuck et al., 2007; Grupp et al., 2008; Heiser et al., 2012), aversive odorants that stimulate the olfactory nerve alone do not awaken sleeping subjects (Badia et al., 1990; Carskadon and Herz, 2004; Stuck et al., 2007; Grupp et al., 2008; Arzi et al., 2010). Finally, given that implicit learning is an effective path to long-term modification of behavior (Dew and Cabeza, 2011; Janacsek and Nemeth, 2012; Reber, 2013) and is sometimes more effective than explicit learning (Reber and Squire, 1998; Reber et al., 1999; Willingham and Goedert-Eschmann, 1999; Robertson et al., 2004; Li et al., 2007), the inherently implicit nature of sleep-learning may render it particularly effective for modulating behavior.

With all the above in mind, we set out to ask whether conditioning between cigarette odor and profoundly unpleasant odors during sleep would reduce cigarette-smoking behavior compared with similar conditioning during wakefulness. Moreover, given compelling evidence that learning is sleep-stage dependent 
(Walker and Stickgold, 2006; Diekelmann and Born, 2010; Landmann et al., 2014), we set out to separately test conditioning during stage 2 sleep and rapid eye movement (REM) sleep.

\section{Materials and Methods}

Participants. Seventy-six otherwise healthy smokers wishing to quit smoking (mean age, $28.7 \pm 5.2$ years; 26 women) participated in the study after providing written informed consent to procedures approved by the Lowenstein Hospital Helsinki Committee. Participants were screened before the procedure in the laboratory for chronic use of medication, history of nasal insults, sleep disorders, or abnormal sleep habits based on self-report. In addition, postexperimental (PE) subject data were screened for sleep disorders, specifically for obstructive sleep apnea using standard polysomnography and respiration criteria. All subjects were told the intervention could potentially reduce smoking, but they were not informed on intervention specifics. Sleep subjects were told that they might or might not receive odors during the night, but they were not informed on experimental procedures or conditions (implicit). Awake subjects were informed about the specific experimental procedure (explicit). Overall, 10 subjects were excluded following insufficient continuous sleeping time such that no odors were delivered $(n=4)$, technical problems with odor delivery $(n=1)$, or failure to fully follow the proto$\operatorname{col}(n=5)$. The remaining 66 subjects had a mean cigarette consumption of $13.9 \pm 5.4$ cigarettes per day over the past $11.5 \pm 5.8$ years.

Odorants and delivery. All experiments were conducted in a designated olfaction sleep laboratory. The experimental room was coated in stainless steel to prevent ambient odor adhesion and was subserved by highefficiency particulate air and carbon filtration to further assure an odorfree environment. Cigarette odor was extracted from smoked cigarette filters dissolved in propylene glycol (CAS 57-55-6, Sigma-Aldrich) and stirred at $65^{\circ} \mathrm{C}$ for several hours. Unpleasant odorants were ammonium sulfide 1\% dissolved in water (AmSu; CAS 12135-76-1, Sigma-Aldrich) and a scent emulating rotten fish (RF; Sensale) that we have used before in sleep experiments and found that it did not awaken or arouse the subjects (Arzi et al., 2012). All odors were delivered through a nasal mask at low, nontrigeminal concentrations by a computer-controlled airdilution olfactometer placed in an adjacent room. The olfactometer generated no visual, auditory, tactile, humidity, or thermal cues as to the alteration between odor and clean air (Johnson and Sobel, 2007). Cigarette odor duration was $5 \mathrm{~s}$, unpleasant odor duration was $3 \mathrm{~s}$, and these were embedded within a constant clean airflow of $6 \mathrm{~L}$ per minute.

Polysomnography. Sleep was recorded by standard polysomnography (Iber, 2007). Electroencephalogram (EEG; obtained from C3 and C4, referenced to opposite mastoid), electro-oculogram (placed $1 \mathrm{~cm}$ above or below and laterally of each eye, referenced to opposite mastoid), electromyogram (located bilaterally at the chin), and respiration were all recorded (Power-Lab 16SP and Octal Bio Amp ML138, ADInstruments) at $1 \mathrm{kHz}$ (Arzi et al., 2010, 2012). Nasal respiration was measured using a spirometer (ML141, ADInstruments) and high-sensitivity pneumotachometer (\#4719, Hans Rudolph) in line with the vent ports of the nasal mask (Johnson et al., 2006).

Nasal airflow analysis. Nasal airflow is sensitive to sleep stage (Douglas et al., 1982; Krieger, 1985; Pagliardini et al., 2012). To prevent sleep-stage bias and to enable a comparison of the sniff response between sleep stages, we normalized the nasal inhalation duration for each event as in previous studies (Arzi et al., 2010, 2012). Specifically, for each trial, we calculated during sleep the baseline sniff duration by averaging the duration of three nasal inhalations preceding trial onset. We then divided the sniff response for each trial by the trial baseline.

EEG analysis. EEG absolute power spectral analysis in the $\delta(0.5-4$ $\mathrm{Hz}), \theta(4-8 \mathrm{~Hz}), \alpha(8-12 \mathrm{~Hz}), \sigma(11-16 \mathrm{~Hz})$, and $\beta(12-24 \mathrm{~Hz})$ ranges was conducted using Matlab functions for fast Fourier transform of $20 \mathrm{~s}$ windows before and after odor onset. Because there was no difference in effects between C3 and C4, data were collapsed across electrodes for final analysis and presentation.

Procedures. On each day for $7 \mathrm{~d}$ before the experimental procedure, subjects completed a smoking diary, detailing the number of cigarettes smoked, and a smoking habits questionnaire, evaluating their addiction level (Etter et al., 2003). On the experimental night, subjects in the sleep implicit group arrived at the olfactory sleep laboratory at a self-selected time, based on their usual sleep pattern, typically at 11:00 P.M., and were fitted with polysomnography devices. Then, each subject rated the intensity and pleasantness of the odorants using a visual-analog scale (VAS). The VAS line was $145 \mathrm{~mm}$ long, and later analysis relates to the millimetric point of line crossing. Subjects also judged the authenticity of the cigarette odor by VAS, rating its similarity to cigarettes. Next, subjects were left alone in the darkened room to be observed from the neighboring control room via infrared video camera and one-way observation window. The experimenters observed the real-time polysomnography reading, and initiated the experimental protocol $\geq 1 \mathrm{~h}$ after the subject fell asleep and after they determined that the subject had entered the desired sleep stage.

Subjects in the wake explicit group arrived at the olfactory sleep laboratory at a self-selected time between 9:00 A.M. and 7:00 P.M. They were comfortably seated in an armchair in front of a computer screen and rated the intensity and pleasantness of the odorants in addition to the similarity of the cigarette odor. Subjects were then left alone in the room to be observed from the neighboring control room via video camera and one-way observation window. To prevent the subjects from falling asleep, an emotionally neutral nature video film was presented on the monitor in front of them

The olfactory aversive conditioning protocol consisted of partialreinforcement trace conditioning in which cigarette odor was followed by unpleasant odors. The conditioned (cigarette odor) and nonconditioned (unpleasant odors) stimuli were partially reinforced at a ratio of 2:1 (Fig. 1A); on reinforced trials (two-thirds of trials), a 5 s cigarette odor was triggered by the respiratory trace and paired with a $3 \mathrm{~s}$ unpleasant odor (either AmSu or RF) also triggered by the respiratory trace. Respiratory trace triggering of the odor was by exhalation, as this promised consistent odor exposure at next inhalation onset. Trace duration (the time between cigarette odor offset and unpleasant odor onset) was variable $(3.7 \pm 3.3 \mathrm{~s})$ because of triggering off of respiration, which is intrinsically variable across subjects. On nonreinforced trials (one-third of trials), cigarette odor was generated without an ensuing unpleasant odorant (cigarette odor alone). Stimuli were generated in blocks of 30 trials (10 trials reinforced with $\mathrm{AmSu}, 10$ reinforced with $\mathrm{RF}$, and 10 nonreinforced with cigarette odor only, randomized across the block). This protocol was initiated in stage 2 sleep $(n=12)$, in REM sleep $(n=12)$, and in wakefulness $(n=10)$.

The "unpleasant odors alone" control protocol (Fig. 1B) contained the same experimental paradigm as the olfactory aversive conditioning, yet cigarette odor (the conditioned stimulus) was replaced by clean air. This protocol was initiated in either stage $2(n=11)$ or REM $(n=11)$ sleep.

The "nonconditioned" control protocol (Fig. 1C) contained the same number of odor exposures as in the olfactory aversive conditioning protocol (30 trials of cigarette odor, 10 trials of $\mathrm{AmSu}$, and 10 trials of RF), yet they were presented in randomized order. This protocol was initiated in stage 2 sleep $(n=10)$.

In all sleep experiments, if an arousal or awakened state was detected in the ongoing polysomnographic recording, the experiment was immediately stopped until stable sleep was resumed and then continued until the end of the block. Because the experiment was halted following arousal or wakefulness, different subjects had different numbers of trials with different intertrial-interval durations (non-normal distribution with a median of $66 \mathrm{~s}$ ). Intertrial interval was $132 \pm 189 \mathrm{~s}$, and there were $10.0 \pm 4.6$ presentations per condition.

The experienced technician who halted and started the experiment on-line was not the same technician who later blindly scored sleep offline. Approximately $30 \mathrm{~min}$ after awakening in the morning, subjects again rated the intensity and pleasantness of the odorants in addition to the similarity of the cigarette odor. Finally, subjects completed a smoking diary on each of the $7 \mathrm{~d}$ after coming to the sleep laboratory, detailing the number of cigarettes smoked each day. 


\section{Results}

The odorants used were unpleasant as intended

An ANOVA on VAS pleasantness rankings with conditions of odor (cigarettes, $\mathrm{AmSu}, \mathrm{RF}$ ) and group (conditioning stage 2, conditioning REM, conditioning wake, unpleasant odors stage 2, unpleasant odors REM, nonconditioned stage 2), revealed a main effect of odor $\left(F_{(2,120)}=32.85, p<\right.$ 0.0005; Fig. $2 A$ ) reflecting that both $\mathrm{AmSu}$ and RF were significantly less pleasant than cigarette odor (cigarettes, $48 \pm 34$ $\mathrm{mm}$; AmSu, $18 \pm 21 \mathrm{~mm}$; RF, $21 \pm 24$ $\mathrm{mm}$; all $t_{(65)}>6.13$, all $\left.p<0.000005\right)$, no main effect of group $\left(F_{(5,60)}=1.21, p>\right.$ $0.32)$, and no interaction between group and odor $\left(F_{(10,120)}=1.24, p>0.27\right)$. Given that the VAS ranged from very unpleasant $(0 \mathrm{~mm})$ to very pleasant $(145$ $\mathrm{mm})$, with the middle $(72.5 \mathrm{~mm})$ denoting neutral, we asked whether the odors were significantly different from neutral. We found that all three odors were significantly less pleasant than neutral (cigarette $t_{(65)}=5.73, p<3^{\star} \mathrm{e}^{-7}$; AmSu $t_{(65)}=$ 20.83, $p<2^{\star} \mathrm{e}^{-28}$; RF $t_{(65)}=17.67, p<$ $\left.4^{\star} \mathrm{e}^{-24}\right)$.

The same ANOVA on intensity rankings revealed a main effect of odor $\left(F_{(2,120)}=\right.$ 28.01, $p<0.0005$; Fig. $2 B)$, reflecting that the unpleasant odors were significantly more intense compared with the cigarette odor (cigarettes, $69 \pm 39 \mathrm{~mm}$; AmSu, $107 \pm 38 \mathrm{~mm}$; RF, $112 \pm 34 \mathrm{~mm}$; all $t_{(65)}$ $>5.26$, all $p<6^{\star} \mathrm{e}^{-8}$ ), and there was no main effect of group or interaction (all $F<0.98$, all $p>0.44$ ).

\section{The odorants used did not awaken subjects}

Several studies have indicated that nontrigeminal odorants presented during sleep do not awaken subjects (Badia et al., 1990; Carskadon and Herz, 2004; Stuck et al., 2007; Arzi et al., 2010). To verify that this was the case here, an experienced sleep technician who was not the same sleep technician that ran the experiment, applied polysomnography standards for arousal and wakefulness (Iber, 2007). Of 1690 trials in 56 subjects, 177 trials (10.5\%) were followed by an observable arousal or awakening within $30 \mathrm{~s}$ of trial onset. Seven subjects had no arousals surrounding any trial, and the remaining subjects had between 1 and 10 arousals (mean, $3.2 \pm 2$ ). All trials preceded or followed by an arousal or wakefulness were omitted from ensuing analyses. An additional 145 trials out of the 1690 trials $(8.6 \%)$ were omitted due to recording artifacts.

To further characterize the brain response to odors during sleep, we analyzed the EEG spectral properties in all sleep subjects $\mathrm{X} 10$
A Experiment time line

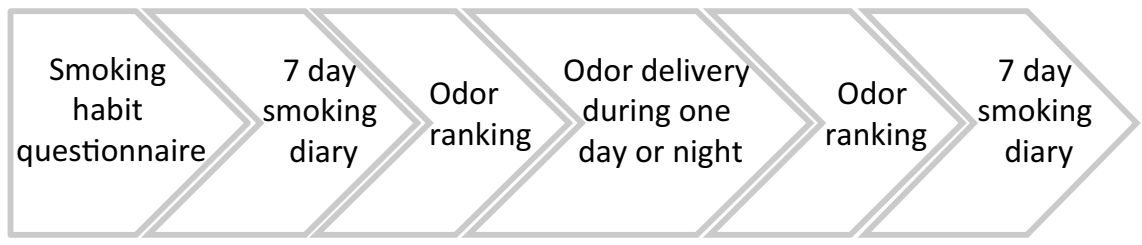

B Polysomnography, respiration and odor delivery settings

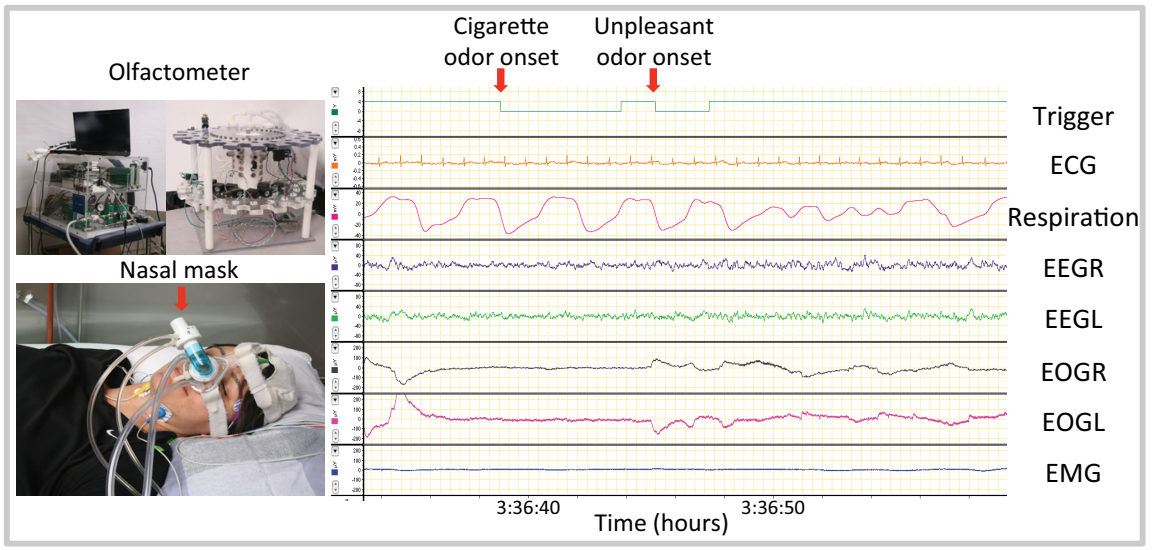

\section{Odor delivery procedure}

i) Olfactory aversive conditioning: $\mathrm{X} 10$ $\mathrm{X} 10$

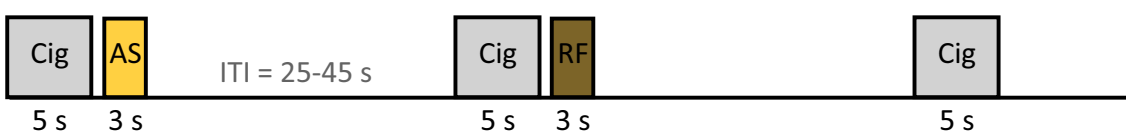

ii) Unpleasant odors:

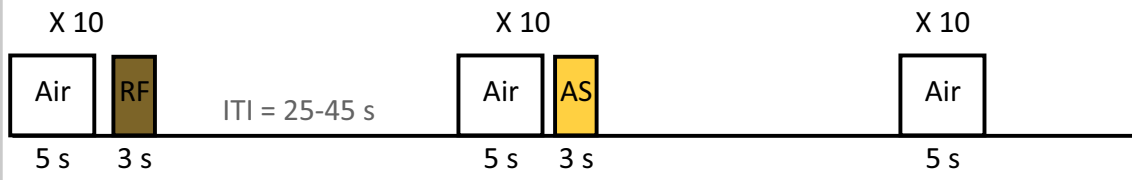

iii) Cigarette and unpleasant odors non-conditioned:

\begin{tabular}{|c|c|c|c|c|c|}
\hline$\times 30$ & & $\times 10$ & $\times 10$ & & \\
\hline Cig & $\mathrm{ITI}=25-45 \mathrm{~s}$ & AS & RF & Cig & Cig \\
\hline $5 \mathrm{~s}$ & & $3 s$ & $3 s$ & $5 \mathrm{~s}$ & $5 \mathrm{~s}$ \\
\hline
\end{tabular}

Figure 1. Experimental protocols. $\boldsymbol{A}$, Experimental timeline. $\boldsymbol{B}$,Experimental setup. Top left, Theolfactometer (odorgenerating device). Bottom left, A subject with polysomnography devices and nasal mask for odor administration with pneumotachograph for precise sniff recording. Right, Polysomnography and respiration recording. The experimenter manually initiated odor onset according to the desired sleep stage, REM sleep in this case. Ci, The main experimental protocol. Olfactory partial-reinforcement aversive trace conditioning between cigarette odor (Cig) and unpleasant odors. Stimuli were generated in blocks of 30 trials: 10 reinforced trials with unpleasant AmSu odor (AS; yellow), 10 reinforced trials with unpleasant RF odor (brown) and 10 nonreinforced trials (cigarette odor alone; gray). Cii, The control protocol of unpleasant odors alone. Unpleasant odor administration in the same experimental procedure as in $A$, yet cigarette odor was replaced with clean air. Ciii, Thenonconditioned control protocol. Cigarette and unpleasant odor administration in randomized order such that the cigarette odor and unpleasant odors were nonconditioned.

in artifact-free $20 \mathrm{~s}$ epochs before and after odor onset in the following frequency bands: $\delta(0.5-4 \mathrm{~Hz}), \theta(4-8 \mathrm{~Hz}), \alpha(8-12$ $\mathrm{Hz}), \sigma(11-16 \mathrm{~Hz})$, and $\beta(12-24 \mathrm{~Hz})$. Two participants were excluded from this analysis due to noisy EEG recordings, and two 


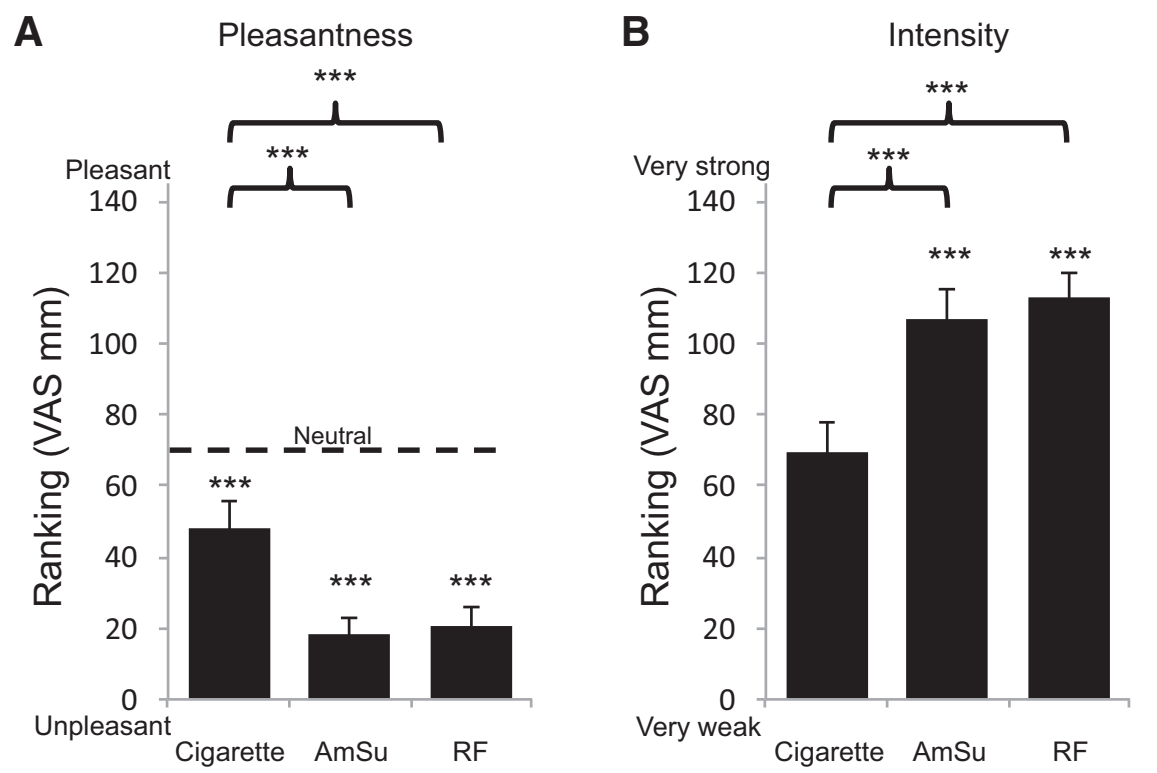

Figure 2. Odors were unpleasant as intended. Odorant ranking on a visual analog scale ( $145 \mathrm{~mm}$ long). $\boldsymbol{A}$, Pleasantness ranking ranging from very unpleasant $(0)$ to very pleasant (145). The dotted line denotes neutral valence. $\boldsymbol{B}$, Intensity ranking ranging from very weak (0) to very strong (145). ${ }^{* * *} p<0.0005$.

participants had no artifact-free trials in the unpleasant odors conditions. We analyzed the EEG power in $20 \mathrm{~s}$ epochs before trial onset and 20 s epochs after each unpleasant odor onset (AmSu or RF), then calculated the percentage change [(power after - power before)/ power before] and conducted an ANOVA on the EEG power percentage change with conditions of odor $(\mathrm{AmSu}, \mathrm{RF})$, sleep stage (stage $2, \mathrm{REM})$, and frequency [ $\delta(0.5-4 \mathrm{~Hz}), \theta(4-8 \mathrm{~Hz}), \alpha(8-12$ $\mathrm{Hz}), \sigma(11-16 \mathrm{~Hz})$, and $\beta(12-24 \mathrm{~Hz})]$. We found a main effect of frequency $\left(F_{(4,200)}=8.87, p<0.001\right)$, reflecting an increase in the power of the $\delta$ frequency band, no main effect of odor $\left(F_{(1,50)}=0.02\right.$, $p>0.88)$, no main effect of stage $\left(F_{(1,50)}=2.37, p>0.13\right)$, and a significant interaction between frequency and stage $\left(F_{(4,200)}=2.52\right.$, $p<0.05$ ), reflecting higher percentage change during REM. No other significant interactions were found (all $p>0.72$ ). In addition, in the groups that were exposed to cigarette odor (conditioning and nonconditioned groups only), we repeated the same ANOVA but with condition of odor including cigarette odor (cigarettes, AmSu, $\mathrm{RF})$. Again, we found a main effect of frequency $\left(F_{(4,124)}=5.42, p<\right.$ 0.0001 ; Fig. 3), reflecting an increase in the power of the $\delta$ frequency band, no main effect of odor $\left(F_{(2,62)}=0.27, p>0.77\right)$, no main effect of stage $\left(F_{(1,31)}=0.01, p>0.77\right)$, and no significant interactions (all $p>0.08)$. Planned comparisons revealed a significant enhancement in $\delta$ power following RF $\left(11.6 \pm 41.0 \%, t_{(51)}=2.30, p<0.05\right.$; Fig. $3 A)$ and $\mathrm{AmSu}\left(10.5 \pm 35.9 \%, t_{(51)}=2.12, p<0.05\right.$; Fig. $\left.3 B\right)$, and $\mathrm{a}$ trend following cigarette odor $\left(10.1 \pm 32.6 \%, t_{(33)}=1.81, p=0.08\right.$; Fig. $3 C)$. In addition there was a trend in $\sigma$ following RF $(-4.2 \pm$ $\left.16.7 \%, t_{(51)}=1.81, p=0.08\right)$. There was no significant change in any of the other frequency bands following odor administration (all $p>0.14$ ). These results are consistent with previous studies and imply that odors did not awaken the subject. Moreover, the odor induced $\delta$-wave enhancement, which may imply sleepprotective odor properties.

\section{Odorant properties were reflected in the sniff response during sleep}

Given that the odors did not awaken the subject, one may ask whether there is any evidence of the brain at all registering the odors, as this is likely necessary for conditioning. Although nontrigeminal odors do not awaken the subject, they nevertheless modify the sniff response in a predicted manner, driving weaker sniffs for unpleasant odors (Arzi et al., 2012). To ask whether this was also the case here, we compared sniffs following the unpleasant odorants during sleep.

We calculated sniff duration for three nasal inhalations before each trial onset (averaged for a single baseline for each trial) and for three sniffs after each unpleasant odor onset. Then we normalized the sniff duration by dividing each of the three sniffs after unpleasant odor onset by trial baseline. An ANOVA on sniff duration for the condition of sniff (Sniff1, Sniff2, Sniff3) revealed a main effect of $\operatorname{sniff}\left(F_{(2,54)}=4.44, p<0.05\right)$. Planned comparisons showed a significant reduction from baseline in the first sniff after odor onset (percentage change, $3.8 \%$; $t_{(54)}$ $=2.86, p<0.01$; Fig. 4 ), but not in the second and third sniff after odor onset (all $t_{(54)}<0.44$, all $\left.p>0.66\right)$. These odor-induced sniffing patterns of reduced sniffs for the unpleasant odors during sleep are consistent with previous studies, and imply that the sleeping brain indeed registered odor presence and quality.

\section{Conditioning during sleep reduced cigarette-smoking behavior but conditioning in wakefulness did not}

Given that the odors did not awaken the subject, but were likely registered by the brain as evidenced in the odor-specific sniff response, we set out to ask whether olfactory aversive trace conditioning during stage 2 sleep, REM sleep, and wakefulness influenced later smoking behavior. We calculated a baseline smoking rate for each subject reflecting the average number of smoked cigarettes across the $7 \mathrm{~d}$ preceding the study. There was no difference between groups in baseline smoking rate (stage 2, $13.3 \pm 6.3$ cigarette per day; REM, $12.7 \pm 3.7$ cigarette per day; wake, $12.7 \pm 6.0$ cigarette per day; all $t<0.25$, all $p>0.80$ ) or addiction level (stage 2, $43.8 \pm 6.4$; REM, $46.2 \pm 4.8$; wake, $43.5 \pm 7.7$; all $t<1.0$, all $p>0.33$ ). Next, we calculated for each subject the average percentage change from baseline of smoked cigarettes across the $7 \mathrm{~d}$ following the study and conducted an ANOVA with condition of group (stage 2 sleep, REM sleep, wake). We found a main effect of group $\left(F_{(2,31)}=3.77, p<0.05\right)$ reflecting a significant reduction in smoking following conditioning during stage 2 sleep $\left(-34.4 \pm 30.9 \%, t_{(11)}=3.92, p<0.005\right)$ and REM $\left(-11.9 \pm 19.2 \%, t_{(11)}=2.35, p<0.05\right)$, but not wake $(-6.6 \pm$ $\left.25.3 \%, t_{(9)}=0.85, p>0.42\right)$, and a larger reduction in smoking following conditioning during stage 2 sleep compared with REM $\left(t_{(11)}=2.14, p<0.05\right)$ and wake $\left(t_{(11)}=2.27, p<0.05\right)$. In addition, planned comparisons revealed that in the stage 2 group there was a significant reduction in the number of smoked cigarettes between the baseline and PE days 1-7 [PE day 1 reduction, $-47.9 \pm 38.6 \%$; PE day 2 reduction, $-40.8 \pm 33.2 \%$; PE day 3 reduction, $-42.1 \pm 31.5 \%$; $\mathrm{PE}$ day 4 reduction, $-36.0 \pm 36.3 \%$; PE day 5 reduction, $-23.9 \pm 38.6 \%$; PE day 6 reduction, $-25.6 \pm$ $47.2 \%$; PE day 7 reduction, $-27.8 \pm 33.4 \%$; all $p<$ false discovery rate (FDR) $\alpha$; Fig. $5 A$ ]. In the REM group there was a significant reduction in PE days 2 and 4 (PE day 2 reduction, $-33.3 \pm$ 
28.6\%; PE day 4 reduction, $-17.6 \pm$ $22.7 \%$; all $p<$ FDR $\alpha$; Fig. $5 A$ ), a trend in $\mathrm{PE}$ days 1 and 3 (PE day 1 reduction, $-20.8 \pm 36.2 \%, p=0.058$; $P E$ day 3 reduction, $-17.3 \pm 27.2 \%, p=0.062$ ), and no reduction from baseline in PE days 5-7 (PE day 5 reduction, $-5.3 \pm 25.7 \%$; $\mathrm{PE}$ day 6 reduction, $-3.1 \pm 32.4 \%$; PE day 7 reduction, $-7.7 \pm 36.0 \%$; all $p>$ FDR $\alpha$; Fig. $5 A$ ). In the wake group there was no significant reduction in the number of smoked cigarettes between the baseline and any of the following 7 PE days (PE day 1 reduction, $-15.7 \pm 32.2 \%$; $\mathrm{PE}$ day 2 reduction, $-4.3 \pm 36.1 \%$; $\mathrm{PE}$ day 3 reduction, $-12.0 \pm 26.2 \%$; PE day 4 reduction, $-3.6 \pm 36.1 \%$; PE day 5 reduction, $-3.3 \pm$ $35.5 \%$; PE day 6 reduction, $-3.3 \pm 23.6 \%$; $\mathrm{PE}$ day 7 reduction, $-3.9 \pm 22.2 \%$; all $p>$ FDR $\alpha$; Fig. $5 A$ ).

To characterize the influence of time on the reduction in smoking, we calculated the percentage change of smoked cigarettes from baseline in the first half (PE days 1-3) and second (PE days 5-7) half of the experiment, and conducted an ANOVA with conditions of group (stage 2 sleep, REM sleep, wake) and time (first half, second half). We found a main effect of time $\left(F_{(1,31)}=28.87, p<0.0001\right.$; Fig. $5 B)$ reflecting a greater reduction in smoking in the first half, a main effect of group $\left(F_{(2,31)}=3.66, p<0.05\right.$; Fig. $\left.5 B\right)$, and no interaction between time and group $\left(F_{(2,31)}=2.79, p=0.77\right)$. Planned comparisons revealed that following conditioning during stage 2 sleep there was a significant reduction in smoking in the first half $\left(-43.6 \pm 31.1 \%, t_{(11)}=4.23\right.$, $p<0.005)$ and second half $(-24.3 \pm$ $\left.33.6 \%, t_{(11)}=2.98, p<0.05\right)$ of the experiment. However, following conditioning during REM, there was a significant reduction only in the first half $(-23.8 \pm$ $\left.21.8 \%, t_{(11)}=3.42, p<0.01\right)$ but not in the second half $\left(1.8 \pm 24.4 \%, t_{(11)}=0.40\right.$, $p>0.69)$ of the experiment, and that the reduction in the second half was significantly greater following conditioning during stage 2 compared with REM $\left(t_{(22)}=\right.$ $2.17, p<0.05$; Fig. $5 B)$. In addition, conditioning during wakefulness did not reduce smoking in either the first half $(-10.7 \pm$ $\left.25.5 \%, t_{(9)}=1.31, p>0.22\right)$ or second half $\left(-3.5 \pm 24.9 \%, t_{(9)}=\right.$ $0.48, p>0.64$ ) of the experiment.

To characterize the influence of olfactory aversive conditioning on cigarette smoking across the $7 \mathrm{~d}$ period following conditioning, we calculated the percentage change of smoked cigarettes from baseline for each of the $7 \mathrm{~d}$ after conditioning. Then we applied a linear fit for each subject on these percentage change values and extracted the intercept, reflecting the effect size of the change in smoked cigarettes, and slope, reflecting the change during $7 \mathrm{~d}$ after the experiment in smoked cigarettes. We found a
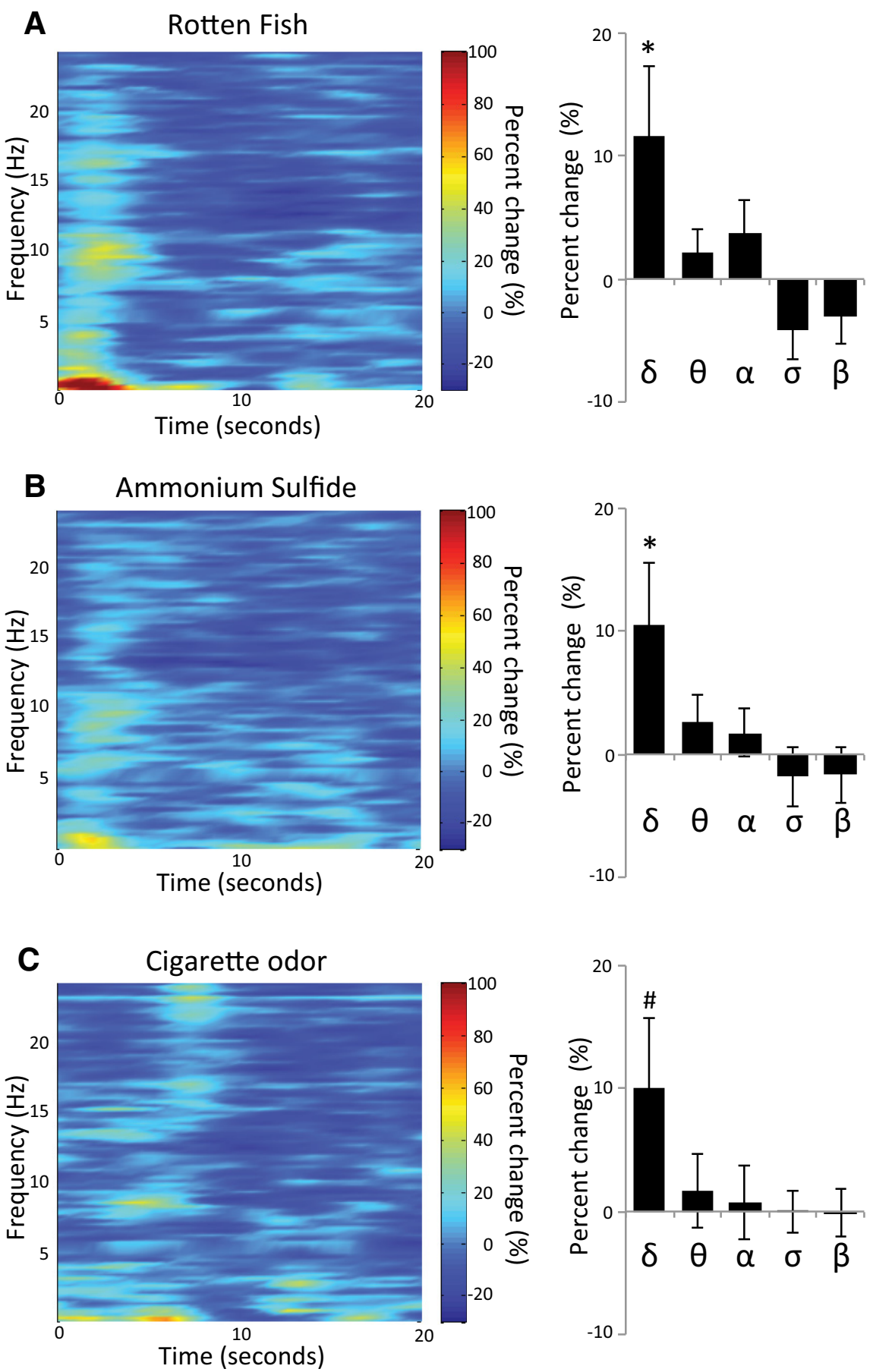

Figure 3. Odors did not awaken subjects. $A-C$, EEG spectral analysis of 20 s after odor onset in the $\delta, \theta, \alpha, \sigma$, and $\beta$ frequency band following $(\boldsymbol{A}) \mathrm{RF},(\boldsymbol{B}) \mathrm{AmSu}$, and $(\boldsymbol{C})$ cigarette odor. ${ }^{*} p<0.05$, \#p $=0.08$.

significantly greater intercept following conditioning during stage 2 sleep compared with wake (stage 2 intercept, $-52.04 \pm$ 34.92; wake intercept, $-13.21 \pm 30.48 ; t_{(20)}=2.7, p<0.05$; Fig. $5 C)$, reflecting a larger reduction in the number of smoked cigarettes in stage 2 , and a trend in the same direction for the slope (stage 2 slope, $4.54 \pm 4.33$; wake slope, $1.64 \pm 2.33 ; t_{(20)}=1.9$, $p=0.073$; Fig. $5 D$ ). In addition, there was a significantly greater slope following conditioning during REM sleep compared with wake (REM slope, $6.09 \pm 6.07$; wake slope, $1.64 \pm 2.33$; $t_{(20)}=$ 2.2, $p<0.05$; Fig. $5 D$ ), reflecting a steeper change in the number 


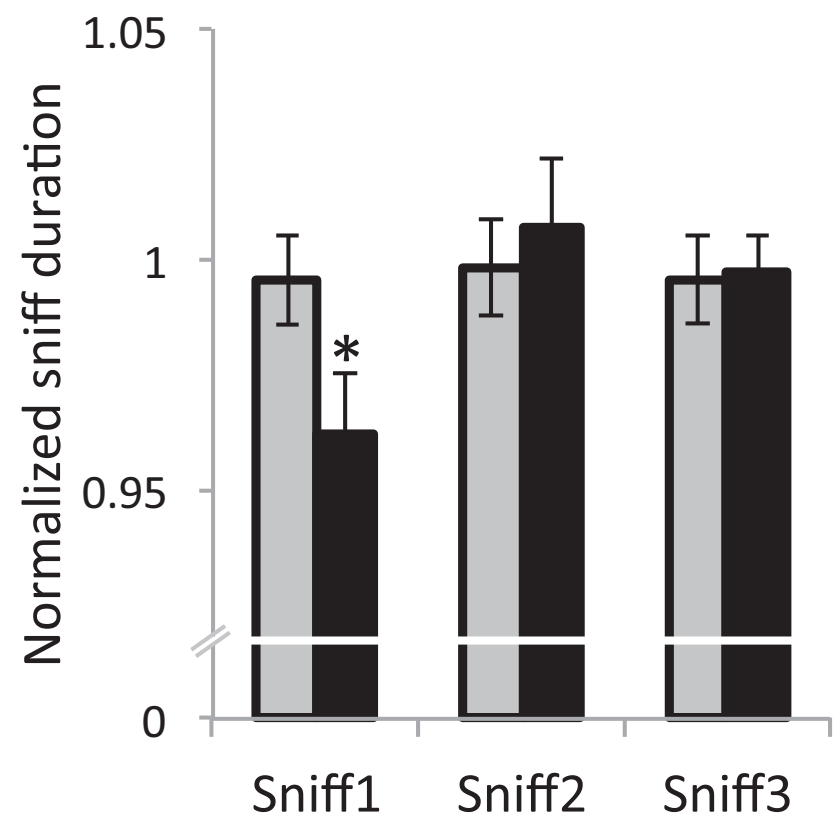

Figure 4. Unpleasant odors reduced first sniff duration during sleep. Normalized sniff duration for three consecutive sniffs following unpleasant odors (black) and cigarette odor (gray) during sleep. The first sniff following unpleasant odor onset was significantly shorter compared with baseline, implying that the sleeping brain indeed registered odor presence and quality. ${ }^{*} p<0.05$.

of smoked cigarettes during the 7 PE days in REM, and a trend in the same direction for the intercept (REM intercept, $-36.29 \pm$ 0.29 ; wake intercept, $13.21 \pm 30.48 ; t_{(20)}=1.8, p=0.085$; Fig. $5 C)$. There were no differences between stage 2 and REM in either the slope or intercept (all $t_{(22)}<1.2, p>0.24$; Fig. $\left.5 C, D\right)$.

To verify that the differences in smoking reduction following conditioning during stage 2 and REM sleep did not result from differences in sleep architecture, number of trials, or the time of night when conditioning was delivered, we compared these parameters between the groups. The stage 2 and REM groups did not differ in total sleep time (stage 2, $346.53 \pm 48.94 \mathrm{~min}$; REM, $368.95 \pm 56.19 \mathrm{~min} ; t_{(1,22)}=0.78, p>0.44$; Table 1$)$, amount of time spent in each sleep stage (all $p>0.30$; Table 1), number of trials (stage 2, $27.42 \pm 4.54$ trials; REM, $25.50 \pm 6.54$ trials; $t_{(1,22)}=0.78, p>0.44$; Table 1$)$ or latency between sleep onset and first trial onset (stage 2, $185.37 \pm 17.37 \mathrm{~min}$; REM, $198.52 \pm$ $74.52 \mathrm{~min} ; t_{(1,22)}=0.78, p>0.44$; Table 1$)$.

These findings suggest that implicit olfactory aversive conditioning during sleep significantly reduced smoking behavior, yet explicit olfactory aversive conditioning during wakefulness did not. Furthermore, reduction in smoking was observed following olfactory aversive conditioning during stage 2 and REM sleep. However, the smoking reduction magnitude and duration was sleep stage-dependent with an enhanced and longer-lasting reduction following stage 2 conditioning.

\section{The effectiveness of conditioning was not associated with altered sensory perception}

To ask whether successful conditioning during sleep was associated with changes in perception of cigarette odor alone, we compared cigarette odor rankings from before and after conditioning. An ANOVA on pleasantness ranking with conditions of ranking time (before, after) and group (stage 2 sleep, REM sleep, wake) revealed no main effect of ranking time $\left(F_{(1,25)}=0.54, p>0.47\right)$, no main effect of group $\left(F_{(1,17)}=0.08, p>0.79\right)$, and a trend in the interaction between ranking time and group $\left(F_{(2,25)}=2.91\right.$, $p=0.073)$. The same ANOVA on intensity and similarity ranking revealed no main effects or interactions (all $F<0.66$, all $p>$ 0.20 ). These results suggest that olfactory aversive conditioning did not change the perception of cigarette odor, and implies that the ensuing influence on cigarette-smoking behavior was not the result of altered sensory perception alone.

\section{Conditioning reduced cigarette-smoking behavior more than sensory exposure alone}

A previous study suggested that exposure to pleasant and unpleasant odors could reduce the urge to smoke regardless of a conditioning paradigm (Sayette and Parrott, 1999). To test whether the observed reduction in smoking following olfactory aversive conditioning during sleep resulted from the pairing between cigarette odor and unpleasant odors, or from the administration of unpleasant odors alone, we conducted a control experiment in which we replicated the conditioning paradigm but used clean air instead of cigarette odor (unpleasant odor group). In this experiment participants were exposed to unpleasant odors alone during stage $2(n=11)$ or REM $(n=11)$ sleep. We compared these results to the original stage 2 and REM conditioning groups. First, we compared the baseline smoking rate and addiction level between the original conditioning groups (stage 2 and REM combined) and the unpleasant odor groups (stage 2 and REM combined) and found no differences (smoking rate: conditioning, $13.0 \pm 5.1$ cigarette per day; unpleasant odors, $14.5 \pm 4.9$ cigarette per day; $t_{(44)}=0.20, p>0.33$; Fig. $6 A$ addiction level: conditioning, $45.0 \pm 5.9$; unpleasant odors, $\left.44.8 \pm 8.6 ; t_{(44)}=0.06, p>0.94\right)$. Next we calculated the percentage change of smoked cigarettes from baseline in the first half (PE days 1-3) and second half (PE days 5-7) of the experiment, and conducted an ANOVA with conditions of group (conditioning, unpleasant odors) and time (first half, second half). We found a main effect of time $\left(F_{(1,44)}=8.48, p<0.01\right.$; Fig. $\left.6 B\right)$, reflecting a greater reduction in smoking in the first half, no main effect of group $\left(F_{(1,44)}=1.51, p>0.23\right)$, but a significant interaction between time and group $\left(F_{(1,44)}=5.3, p<0.05\right.$; Fig. $\left.6 B\right)$, reflecting a larger reduction in smoking in the first half of the experiment in the conditioning group. Planned comparison revealed that in the first half there was a significant reduction in smoking following conditioning $\left(33.7 \pm 28.1 \%, t_{(23)}=8.87, p<0.00005\right)$ and also following unpleasant odors $\left(14.4 \pm 27.3 \%, t_{(21)}=2.48, p<\right.$ $0.05)$. However, the reduction following conditioning was significantly greater $\left(t_{(44)}=2.36, p<0.05\right.$; Fig. $\left.6 B\right)$. There was no significant reduction in the second half of the experiment following conditioning $\left(t_{(23)}=1.74, p>0.096\right)$ or unpleasant odor $\left(t_{(21)}=\right.$ $1.69, p>0.10)$ administration during sleep.

Next, we calculated the percentage change from baseline in the number of cigarettes smoked for each day following the night in the laboratory, applied a linear fit, and extracted the intercept and slope for each subject as before. We found a greater intercept and slope in the conditioning group compared with unpleasant odors group (conditioning intercept, $-44.17 \pm$ 32.51; unpleasant odors intercept, $-15.21 \pm 33.35 ; t_{(44)}=2.98$, $p<0.005$; conditioning slope, $5.31 \pm 5.21$; unpleasant odors slope, $0.63 \pm 7.46 ; t_{(44)}=2.48, p<0.05$; Figure $\left.7 C, D\right)$. These results imply that both olfactory aversive conditioning and unpleasant odor administration alone during sleep reduced smoking behavior, yet the reduction in smoking following olfactory aversive conditioning was approximately double in magnitude of that following unpleasant odors alone. 
Last, to verify that the increased reduction in smoking indeed resulted from the pairing between cigarette odor and unpleasant odors, and not from the administration of cigarette odor or from the different number of odor exposures between the unpleasant odor group (unpleasant odor group: $10 \mathrm{AmSu}$ and $10 \mathrm{RF}$ presentation; 20 total exposures) and the olfactory aversive conditioning group (30 cigarette odor, $10 \mathrm{AmSu}$, and $10 \mathrm{RF}$ presentation; 50 total exposures), we conducted an additional control experiment in which we delivered the same number of aversive and cigarette odors as in the conditioning, but in randomized order rather than paired (nonconditioned group). Because a greater and longer-lasting reduction was evident following conditioning during stage 2 sleep compared with REM sleep, we conducted this control during stage 2 sleep only $(n=10)$ and compared the results to the results of the olfactory aversive conditioning during stage 2 . We found no differences in baseline smoking rate (conditioning, $13.3 \pm 6.3$ cigarette per day; nonconditioned, $15.9 \pm 6.9$ cigarette per day; $t_{(20)}=0.26, p>0.83$; Fig. $7 A$ ) or addiction level (conditioning, $43.8 \pm 6.0$; nonconditioned, $43.4 \pm 7.7$; $\left.t_{(20)}=0.13, p>0.89\right)$ between groups. An ANOVA with conditions of group (conditioning, nonconditioned) and time (first half, second half) revealed a main effect of time $\left(F_{(1,20)}=6.84, p<0.05\right.$; Fig. $\left.7 B\right)$, reflecting a greater reduction in smoking in the first half, no main effect of group $\left(F_{(1,20)}=2.62, p>0.12\right)$, and no significant interaction $\left(F_{(1,20)}=2.78, p>0.11\right)$. Planned comparison revealed that there was no significant reduction in smoking following nonconditioned odors in either the first half $\left(t_{(9)}=1.3, p>0.20\right)$ or second half $\left(t_{(9)}=1.0, p>0.33\right)$ of the experiment. However, as reported before, there was a significant reduction in smoking following conditioning in the first half $\left(43.6 \pm 31.1 \%, t_{(11)}=4.23, p<0.005\right)$ and second half $\left(24.3 \pm 33.6 \%, t_{(11)}=\right.$ $2.98, p<0.05)$, and that the reduction in the first half of the experiment following conditioning was significantly greater following olfactory aversive conditioning compared with nonconditioned odors $\left(t_{(20)}=2.10, p<0.05\right.$; Fig. $\left.7 B\right)$. In addition, linear fit for the percentage change in smoking reduction revealed a greater intercept in the conditioning compared with the nonconditioned group (conditioning group intercept, $-52.04 \pm 34.92$; nonconditioned group intercept, $-21.25 \pm 34.80 ; t_{(20)}=2.06$, $p=0.052$ ), and no effect in the slope (conditioning group slope, $4.54 \pm 4.33$; nonconditioned group slope, $1.74 \pm 4.65 ; t_{(20)}=$ $2.06, p>0.14)$. These results imply that the greater reduction in smoking following olfactory aversive conditioning during sleep compared with odor exposure alone resulted from the pairing 0.005 .
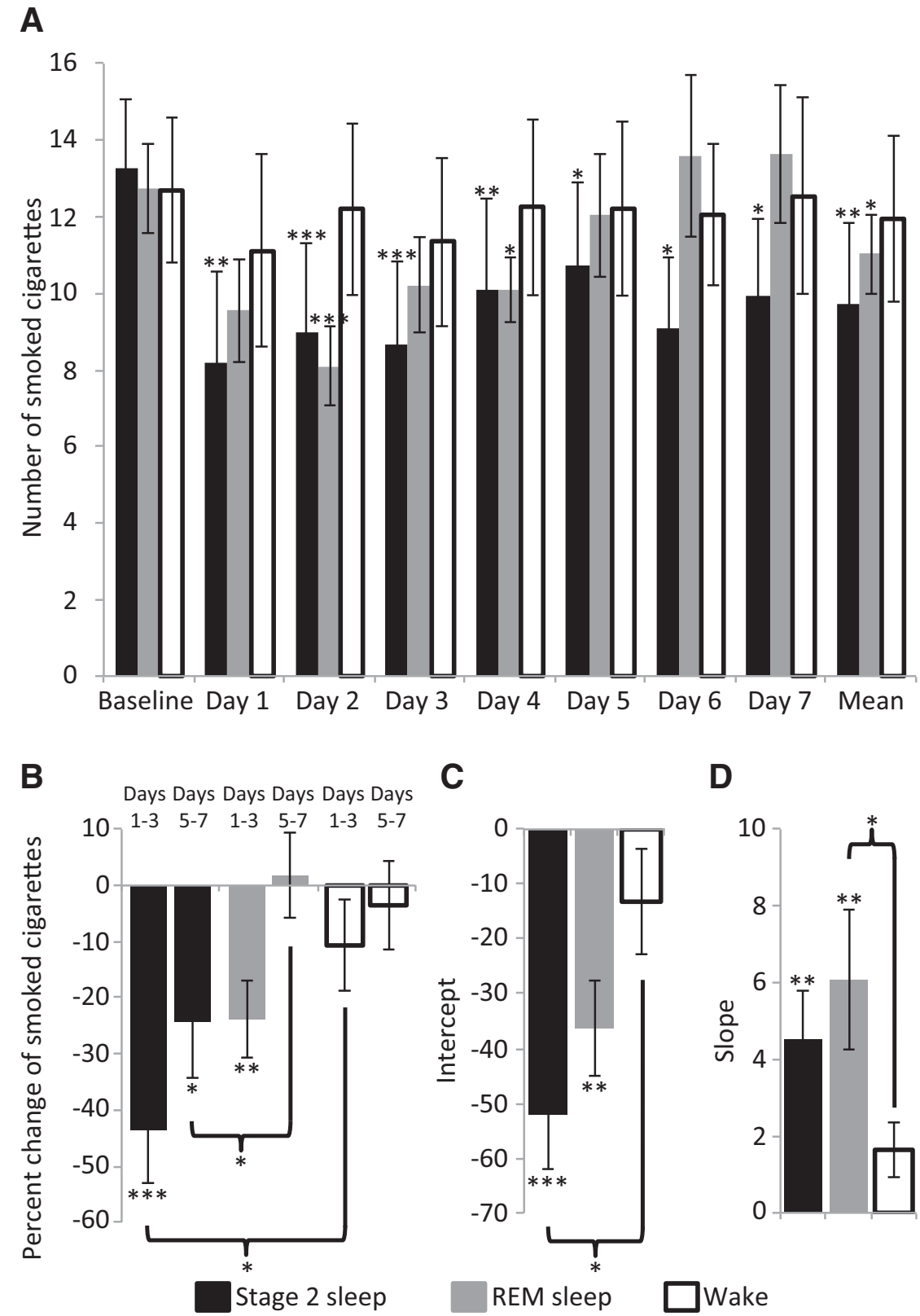

D

Figure 5. Aversive conditioning during sleep reduced subsequent smoking. $\boldsymbol{A}$, Number of smoked cigarettes at baseline and in each day following olfactory aversive conditioning during stage 2 sleep (black), REM sleep (dark gray), and wake (outline). $\boldsymbol{B}$ Percentage change in smoked cigarettes in the first half (days 1-3) and second half (days 5-7) of the experiment following conditioning during stage 2 sleep (black), REM sleep (dark gray), and wake (outline). $\boldsymbol{C}, \boldsymbol{D}$, Intercept ( $\boldsymbol{C}$ ) denoting the effect size of the change in smoked cigarettes and slope $(\boldsymbol{D})$ denoting the change in smoked cigarettes across 7 PE days, following olfactory aversive conditioning during stage 2 sleep (black), REM sleep (dark gray), and wake (outline). ${ }^{*} p<0.05,{ }^{* *} p<0.01,{ }^{* * *} p<$

Table 1. Sleep architecture

\begin{tabular}{lcrcc}
\hline & \multicolumn{1}{c}{ REM group } & \multicolumn{1}{c}{ Stage 2 group } & \multicolumn{1}{c}{$t_{(1,22)}$} & $p$ \\
\hline Wake after sleep onset (\%) & $15.32 \pm 8.34$ & $12.29 \pm 6.78$ & 0.98 & $>0.34$ \\
Stage 1 sleep (\%) & $3.76 \pm 5.67$ & $3.53 \pm 5.97$ & 0.09 & $>0.93$ \\
Stage 2 sleep (\%) & $51.03 \pm 8.34$ & $51.39 \pm 7.62$ & 0.11 & $>0.91$ \\
SWS (\%) & $15.97 \pm 7.61$ & $19.07 \pm 6.82$ & 1.05 & $>0.30$ \\
REM sleep (\%) & $13.92 \pm 3.92$ & $13.70 \pm 7.70$ & 0.09 & $>0.93$ \\
Total sleep time (min) & $368.95 \pm 56.19$ & $346.53 \pm 48.94$ & 0.78 & $>0.44$ \\
Latency from sleep onset to & $198.52 \pm 74.52$ & $185.37 \pm 17.37$ & 0.60 & $>0.56$ \\
$\quad$ & & & & \\
$\quad$ first trial onset (min) & $25.50 \pm 6.54$ & $27.42 \pm 4.54$ & 0.83 & $>0.41$
\end{tabular}



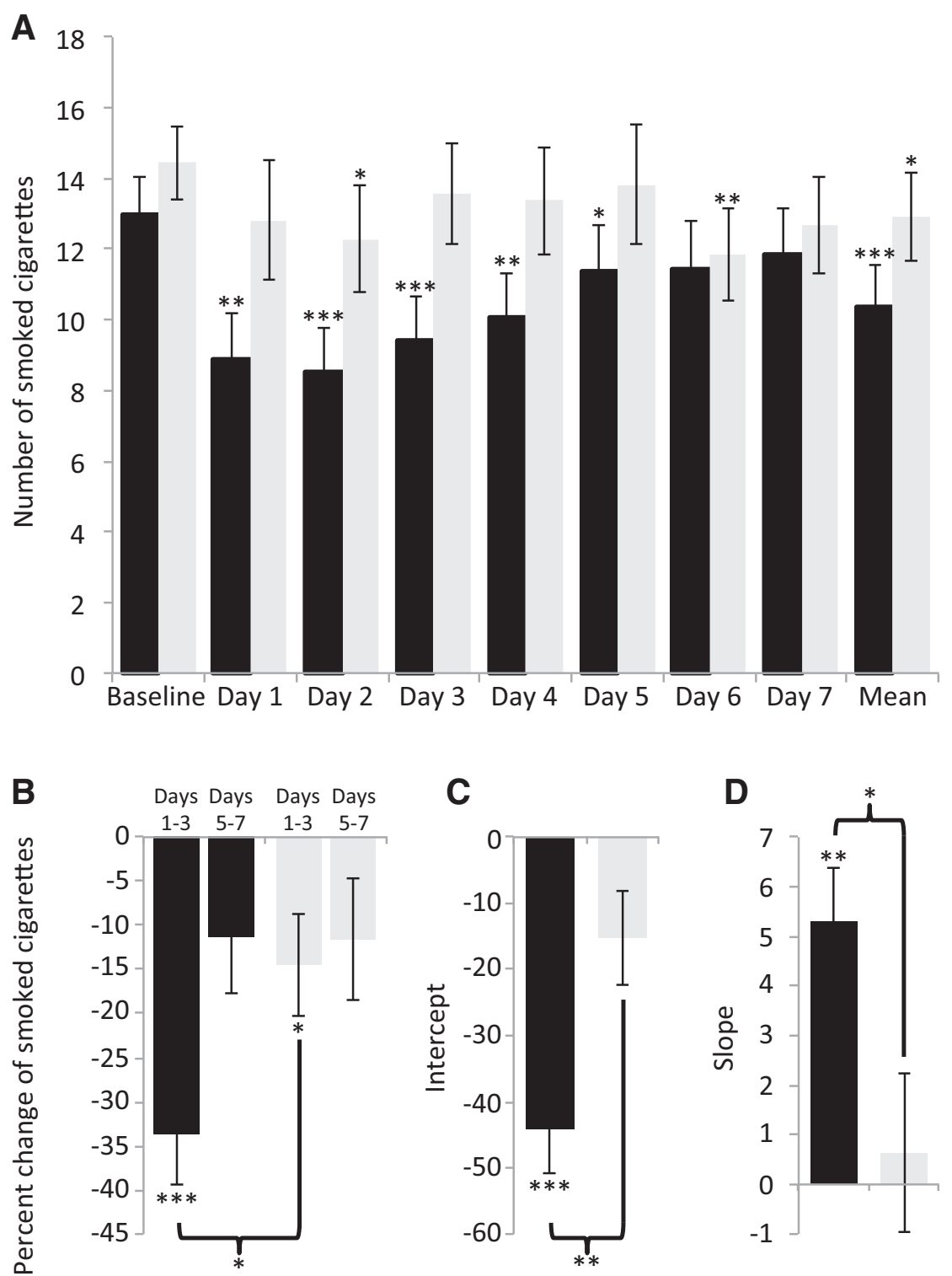

Olfactory aversive Conditioning

Unpleasant odors

Figure 6. Olfactory aversive conditioning reduced smoking more effectively than unpleasant odors alone. $\boldsymbol{A}$, Number of smoked cigarettes at baseline and in each day following olfactory aversive conditioning (black) and unpleasant odor (light gray) administration in sleep (stage 2 and REM combined). $\boldsymbol{B}$, Percentage change in smoked cigarettes in the first half (days $1-3$ ) and second half (days $5-7$ ) of the experiment following olfactory aversive conditioning (black) and unpleasant odors alone (light gray). C, D, Intercept $(\boldsymbol{C})$ denoting the effect size of the change in smoked cigarettes and slope $(\boldsymbol{D})$ denoting the change in smoked cigarettes across 7 PE days following olfactory aversive conditioning (black) and unpleasant odors alone (light gray). ${ }^{*} p<0.05,{ }^{* *} p<0.01$, ${ }^{* * *} p<0.005$.

between cigarette odor and unpleasant odors and not from the administration of the cigarette odor or due to fewer exposures to odor.

\section{Discussion}

We found that a single night of implicit olfactory aversive conditioning between cigarette odor and profoundly unpleasant odors during stage 2 and REM sleep drove a significant reduction in smoking behavior over the ensuing week. Moreover, the reduction in smoking behavior was greater and longer lasting following conditioning in stage 2 versus REM sleep. In contrast, explicit olfactory aversive conditioning during wakefulness did not alter smoking behavior. Consistent with previous findings, presentation of aversive odors alone also reduced ensuing smoking behavior (Sayette and Parrott, 1999), yet this reduction was approximately half of that following conditioning during sleep. Thus, these findings further support the hypothesis that new associations learned during sleep can modify cigarette-smoking behavior.

The different effects of associative learning during wakefulness and sleep are in keeping with several recent studies. For example, using olfactory stimuli for memory reactivation during sleep stabilized memories whereas the same procedure during wakefulness destabilized memories (Diekelmann et al., 2011). In addition, extinction of olfactory contextual fear conditioning was greater when reexposure to the odorant context occurred during sleep compared with wakefulness (Hauner et al., 2013). Moreover, consolidation of emotional memories, though not neutral memories, is more enhanced during sleep than during wakefulness ( $\mathrm{Hu}$ et al., 2006; Wagner et al., 2006; Payne et al., 2008; Baran et al., 2012). Finally, memory reactivation during sleep both strengthened and linked categorically related memories together, while equivalent wake reactivation only strengthened individual memories (Oudiette et al., 2013). Together, our results dovetail with those of these studies to suggest stronger implicit learning in sleep over explicit learning during wakefulness.

Compelling evidence suggests an interaction between sleep stage and learning in general (Walker and Stickgold, 2006; Diekelmann and Born, 2010; Spoormaker et al., 2013; Ackermann and Rasch, 2014; Landmann et al., 2014) and in the specific context of novel conditioning during sleep (Arzi et al., 2012). Here we found that olfactory aversive conditioning during stage 2 resulted in a greater reduction in smoking behavior that lasted for a longer time compared with reduction following similar conditioning in REM sleep. The increased effect in stage 2 is consistent with the expanding literature regarding the role of slow-wave oscillations in memory consolidation of general and olfactory-specific information (Wilson and Yan, 2010; Barnes and Wilson, 2014). In turn, the reduced effect in REM may be viewed as consistent with the rapid forgetting of REM-related memories (dream amnesia; Nir and Tononi, 2010).

Given our attribution of increased learning effects to slowwave oscillations, one may ask why the experiment was not conducted during slow-wave sleep (SWS) rather than in stage 2, 
given that SWS is particularly rich in slow oscillations (Iber, 2007). This decision reflected a tradeoff between the increased prevalence of slow waves in SWS versus the reduced overall time of SWS that occupied in this experiment: only $\sim 17 \%$ of sleep time compared with $\sim 50 \%$ of sleep time in stage 2 (Table 1). Moreover, although SWS clearly plays a role in memory consolidation and reactivation (Plihal and Born, 1999; Gais and Born, 2004; Marshall et al., 2004; Mölle et al., 2004; Peigneux et al., 2004; Rasch et al., 2007; Aeschbach et al., 2008; Antony et al., 2012; Mascetti et al., 2013), such a role is also documented for stage 2 sleep (Gais et al., 2002; Schabus et al., 2004; Clemens et al., 2007; Nishida and Walker, 2007; Andrade et al., 2011; Arzi et al., 2012; Mednick et al., 2013; Tamminen et al., 2013). For example, the amount of improvement in motor skill was significantly correlated with the time spent in stage 2 (Nishida and Walker, 2007). In addition, sleep spindle density, a burst of activity at $\sim 11-16 \mathrm{~Hz}$ that typically occurs during stage 2 (Iber, 2007), increases following declarative learning and correlates with recall performance (Gais et al., 2002). Moreover, pharmacologically modified sleep with increased sleep spindles produced significantly better verbal memory (Mednick et al., 2013). Given that the primary goal of this study was to ask whether sleep conditioning induces behavioral modifications that persist over time, and considering the increased number of events we could expect in stage 2 versus SWS, we concluded that stage 2 conditioning is a safer path for us to test.

Several aspects of olfaction may have rendered it particularly effective for implicit learning in general, and for implicit sleep-learning specifically. First, learning without awareness may be typical for olfaction (Stevenson, 2009): human odor learning can occur with no awareness for the learning process (Stevenson et al., 2000), no awareness about what was learned (Stevenson et al., 2005), and no awareness of the contingent relationship between stimuli (De Houwer et al., 2001; Yeomans and Mobini, 2006). Second, consciously unperceived odorants can have a greater effect on perception and learning compared with perceived odors (Willingham and GoedertEschmann, 1999; Li et al., 2007; Sela and Sobel, 2010). Third, unlike sensory stimuli of other senses, purely olfactory and mildly trigeminal odorants do not awaken subjects (Carskadon and Herz, 2004; Stuck et al., 2007; Grupp et al., 2008; Arzi et al., 2010). Last, cortical processing of olfaction does not initially rely on a thalamic relay (Price, 1990; Sela et al., 2009; Courtiol and Wilson, 2014) and, although a thalamic-type gating function may be implemented in primary olfactory cortex itself (Murakami et al.,

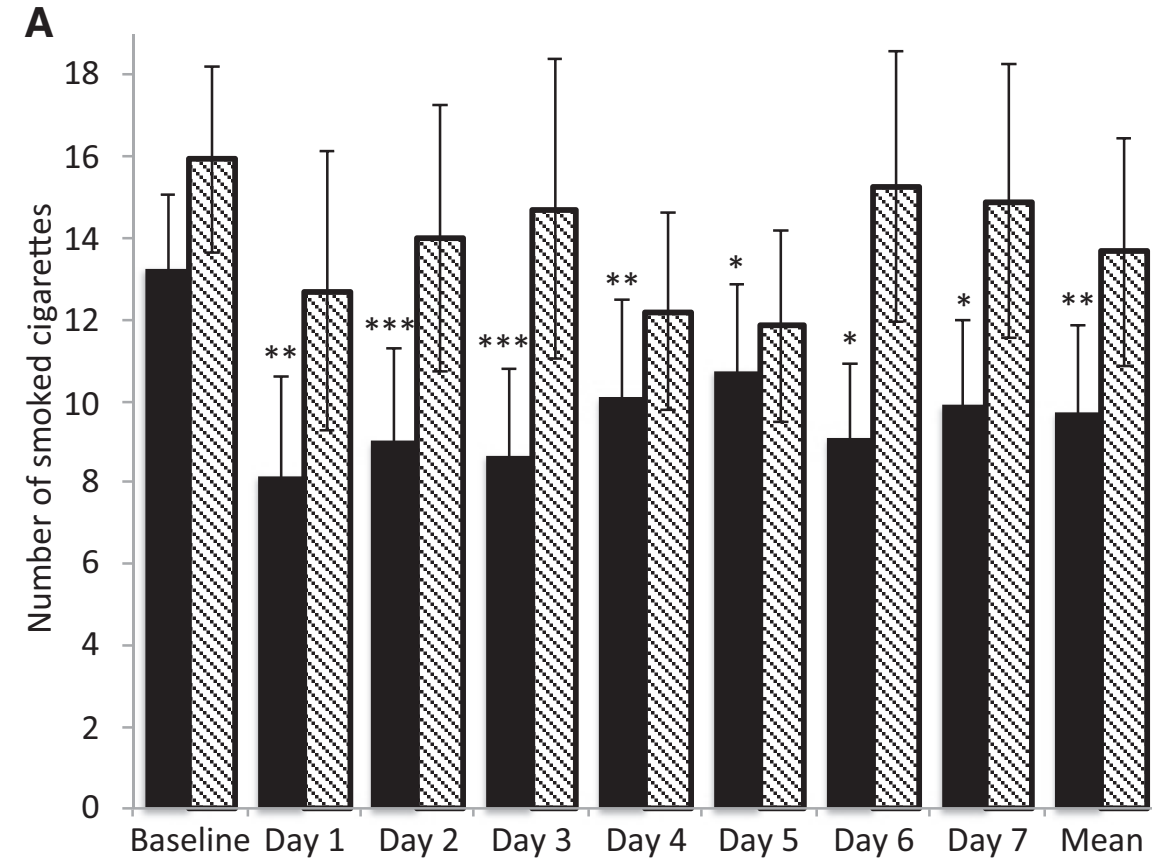

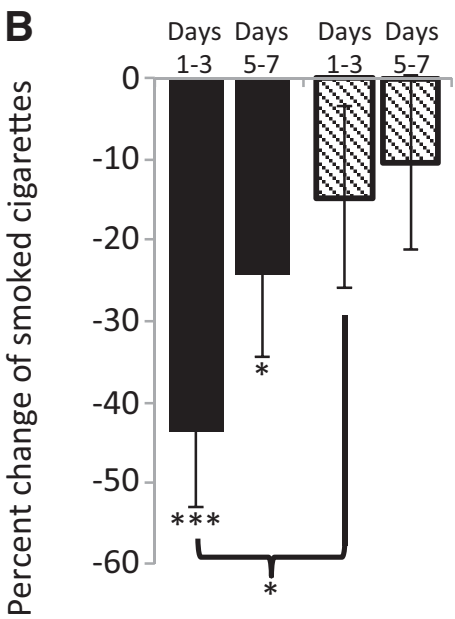

Olfactory aversive Conditioning
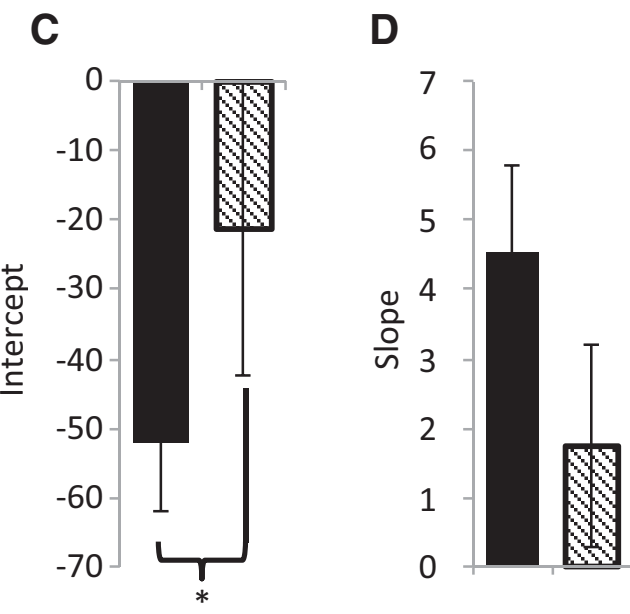

Figure 7. Olfactory aversive conditioning reduced smoking more effectively than nonconditioned odors. $A$, Number of smoked cigarettes at baseline and in each day following olfactory aversive conditioning (black) and nonconditioned odor (striped) administration during stage 2 sleep. $\boldsymbol{B}$, Percentage change in smoked cigarettes in the first half (days 1-3) and second half (days 5-7) of the experiment following olfactory aversive conditioning (black) and nonconditioned odor (striped) administration during stage 2 sleep. $\boldsymbol{C}, \boldsymbol{D}$, Intercept $(\boldsymbol{C})$ denoting the effect size of the change in smoked cigarettes and slope $(\boldsymbol{D})$ denoting the change in smoked cigarettes across 7 PE days following olfactory aversive conditioning (black) and nonconditioned odor (striped) administration during stage 2 sleep. ${ }^{*} p<0.05,{ }^{* *} p<0.01,{ }^{* *} p<0.005$.

2005), the thalamic circumvention may nevertheless provide special status for olfactory information obtained in sleep (Plailly et al., 2008). It is likely that the combination of these characteristics optimized a framework for effective olfactory implicit learning during sleep with later behavioral influences.

Olfaction may have a privileged role not only for implicit learning in general, but also more specifically in the context of addictive behavior, such as smoking. Addiction is associated with direct activation of the reward system (Hyman et al., 2006; Ikemoto et al., 2006; Volkow et al., 2006; Wang et al., 2007; Koob, 2009; Koob and Volkow, 2010). The reward system comprises a 
highly interconnected network of brain regions, including orbitofrontal cortex, amygdala, striatum, nucleus accumbens, and ventral tegmental area (Wise, 1996; O'Doherty, 2004; Pierce and Kumaresan, 2006), and has an important role in reinforcement and aversive learning (Murray, 2007; Bromberg-Martin et al., 2010). The brain circuits of reward and olfaction are highly overlapping. There is a direct connection from the primary olfactory cortex, the piriform cortex, to the amygdala and the orbitofrontal cortex (Haberly, 2001). Moreover, these regions are activated during olfactory processing and also during olfactory aversive conditioning (Gottfried et al., 2002; Gottfried and Dolan, 2004). Furthermore, the functional connectivity between the primary olfactory cortex and the integral parts of the reward system, such as the amygdala, is enhanced during sleep compared with wakefulness (Barnes and Wilson, 2014). The shared anatomy and the enhanced connectivity during sleep between the two systems may enable olfaction to play a role as a unique pathway to modulate reward-related behavior in general and during sleep in particular. All that said, this does not imply direct applicability of our results to the treatment of addiction. This is because treatments of addiction are typically assessed by duration of ensuing abstinence (Shiffman et al., 2008; Pollock et al., 2009; Laniado-Laborín, 2010; Pickens et al., 2011; Stead and Lancaster, 2012; Schlam and Baker, 2013), yet here we merely measured smoking frequency over $7 \mathrm{~d}$. Moreover, although self-report of smoking behavior is considered a largely reliable measure (Patrick et al., 1994), for clinical applications in cigarette addiction the gold standard for smoking behavior includes application of biological markers for nicotine (Chenoweth et al., 2014; Cropsey et al., 2014; Won et al., 2014), and we did not use those here. Thus, future studies may assess the direct applicability of aversive conditioning during sleep to the treatment of addiction. Therefore, we conclude in highlighting our findings as they relate to learning and memory during sleep alone. Here, a single night of olfactory aversive conditioning was followed by reduced smoking behavior that persisted for several days. These results imply that new associations learned during sleep persist over time.

\section{References}

Ackermann S, Rasch B (2014) Differential effects of non-REM and REM sleep on memory consolidation? Curr Neurol Neurosci Rep 14:430. CrossRef Medline

Aeschbach D, Cutler AJ, Ronda JM (2008) A role for non-rapid-eyemovement sleep homeostasis in perceptual learning. J Neurosci 28:27662772. CrossRef Medline

Andrade KC, Spoormaker VI, Dresler M, Wehrle R, Holsboer F, Sämann PG, Czisch M (2011) Sleep spindles and hippocampal functional connectivity in human NREM sleep. J Neurosci 31:10331-10339. CrossRef Medline

Antony JW, Gobel EW, O'Hare JK, Reber PJ, Paller KA (2012) Cued memory reactivation during sleep influences skill learning. Nat Neurosci 15: 1114-1116. CrossRef Medline

Arzi A, Sela L, Green A, Givaty G, Dagan Y, Sobel N (2010) The influence of odorants on respiratory patterns in sleep. Chem Senses 35:31-40. CrossRef Medline

Arzi A, Shedlesky L, Ben-Shaul M, Nasser K, Oksenberg A, Hairston IS, Sobel N (2012) Humans can learn new information during sleep. Nat Neurosci 15:1460-1465. CrossRef Medline

Badia P, Wesensten N, Lammers W, Culpepper J, Harsh J (1990) Responsiveness to olfactory stimuli presented in sleep. Physiol Behav 48:87-90. CrossRef Medline

Baran B, Pace-Schott EF, Ericson C, Spencer RM (2012) Processing of emotional reactivity and emotional memory over sleep. J Neurosci 32:10351042. CrossRef Medline

Barnes DC, Wilson DA (2014) Slow-wave sleep-imposed replay modulates both strength and precision of memory. J Neurosci 34:5134-5142. CrossRef Medline
Born J, Rasch B, Gais S (2006) Sleep to remember. Neuroscientist 12:410424. CrossRef Medline

Bromberg-Martin ES, Matsumoto M, Hikosaka O (2010) Dopamine in motivational control: rewarding, aversive, and alerting. Neuron 68:815-834. CrossRef Medline

Carskadon MA, Herz RS (2004) Minimal olfactory perception during sleep: why odor alarms will not work for humans. Sleep 27:402-405. Medline

Carter N, Henderson R, Lal S, Hart M, Booth S, Hunyor S (2002) Cardiovascular and autonomic response to environmental noise during sleep in night shift workers. Sleep 25:457-464. Medline

Chenoweth MJ, Novalen M, Hawk LW Jr, Schnoll RA, George TP, Cinciripini PM, Lerman C, Tyndale RF (2014) Known and novel sources of variability in the nicotine metabolite ratio in a large sample of treatmentseeking smokers. Cancer Epidemiol Biomarkers Prev 23:1773-1782. CrossRef Medline

Clemens Z, Mölle M, Eross L, Barsi P, Halász P, Born J (2007) Temporal coupling of parahippocampal ripples, sleep spindles and slow oscillations in humans. Brain 130:2868-2878. CrossRef Medline

Courtiol E, Wilson DA (2014) Thalamic olfaction: characterizing odor processing in the mediodorsal thalamus of the rat. J Neurophysiol 111:12741285. CrossRef Medline

Cropsey KL, Trent LR, Clark CB, Stevens EN, Lahti AC, Hendricks PS (2014) How low should you go? Determining the optimal cutoff for exhaled carbon monoxide to confirm smoking abstinence using cotinine as reference. Nicotine Tob Res 16:1348-1355. CrossRef Medline

De Houwer J, Thomas S, Baeyens F (2001) Association learning of likes and dislikes: a review of 25 years of research on human evaluative conditioning. Psychol Bull 127:853-869. CrossRef Medline

Dew IT, Cabeza R (2011) The porous boundaries between explicit and implicit memory: behavioral and neural evidence. Ann N Y Acad Sci 1224: 174-190. CrossRef Medline

Diekelmann S, Born J (2010) The memory function of sleep. Nat Rev Neurosci 11:114-126. Medline

Diekelmann S, Büchel C, Born J, Rasch B (2011) Labile or stable: opposing consequences for memory when reactivated during waking and sleep. Nat Neurosci 14:381-386. CrossRef Medline

Douglas NJ, White DP, Pickett CK, Weil JV, Zwillich CW (1982) Respiration during sleep in normal man. Thorax 37:840-844. CrossRef Medline

Dudai Y (2012) The restless engram: consolidations never end. Annu Rev Neurosci 35:227-247. CrossRef Medline

Etter JF, Le Houezec J, Perneger TV (2003) A self-administered questionnaire to measure dependence on cigarettes: the cigarette dependence scale. Neuropsychopharmacology 28:359-370. CrossRef Medline

Gais S, Born J (2004) Low acetylcholine during slow-wave sleep is critical for declarative memory consolidation. Proc Natl Acad Sci U S A 101:21402144. CrossRef Medline

Gais S, Mölle M, Helms K, Born J (2002) Learning-dependent increases in sleep spindle density. J Neurosci 22:6830-6834. Medline

Gottfried JA, Dolan RJ (2004) Human orbitofrontal cortex mediates extinction learning while accessing conditioned representations of value. Nat Neurosci 7:1144-1152. CrossRef Medline

Gottfried JA, O’Doherty J, Dolan RJ (2002) Appetitive and aversive olfactory learning in humans studied using event-related functional magnetic resonance imaging. J Neurosci 22:10829-10837. Medline

Grupp K, Maurer JT, Hörmann K, Hummel T, Stuck BA (2008) Chemosensory induced arousals during sleep in premenopausal women. Neurosci Lett 444:22-26. CrossRef Medline

Haberly LB (2001) Parallel-distributed processing in olfactory cortex: new insights from morphological and physiological analysis of neuronal circuitry. Chem Senses 26:551-576. CrossRef Medline

Hauner KK, Howard JD, Zelano C, Gottfried JA (2013) Stimulus-specific enhancement of fear extinction during slow-wave sleep. Nat Neurosci 16:1553-1555. CrossRef Medline

Heiser C, Baja J, Lenz F, Sommer JU, Hormann K, Herr RM, Stuck BA (2012) Effects of an artificial smoke on arousals during human sleep. Chemosens Percept 5:274-279. CrossRef

Horne JA, Pankhurst FL, Reyner LA, Hume K, Diamond ID (1994) Fieldstudy of sleep disturbance- effects of aircraft noise and other factors on 5,742 nights of actimetrically monitored sleep in a large subject sample. Sleep 17:146-159. Medline 
Hu P, Stylos-Allan M, Walker MP (2006) Sleep facilitates consolidation of emotional declarative memory. Psychol Sci 17:891-898. CrossRef Medline

Hyman SE, Malenka RC, Nestler EJ (2006) Neural mechanisms of addiction: the role of reward-related learning and memory. Annu Rev Neurosci 29:565-598. CrossRef Medline

Iber C (2007) The AASM manual for the scoring of sleep and associated events: rules, terminology and technical specifications. Darien, IL: American Academy of Sleep Medicine.

Ikemoto S, Qin M, Liu ZH (2006) Primary reinforcing effects of nicotine are triggered from multiple regions both inside and outside the ventral tegmental area. J Neurosci 26:723-730. CrossRef Medline

Janacsek K, Nemeth D (2012) Predicting the future: from implicit learning to consolidation. Int J Psychophysiol 83:213-221. CrossRef Medline

Johnson BN, Sobel N (2007) Methods for building an olfactometer with known concentration outcomes. J Neurosci Methods 160:231-245. CrossRef Medline

Johnson BN, Russell C, Khan RM, Sobel N (2006) A comparison of methods for sniff measurement concurrent with olfactory tasks in humans. Chem Senses 31:795-806. CrossRef Medline

Koob GF (2009) Dynamics of neuronal circuits in addiction: reward, antireward, and emotional memory. Pharmacopsychiatry 42 [suppl 1]:S32-S41. CrossRef Medline

Koob GF, Volkow ND (2010) Neurocircuitry of addiction. Neuropsychopharmacology 35:217-238. CrossRef Medline

Krieger J (1985) Breathing during sleep in normal subjects. Clin Chest Med 6:577-594. Medline

Landmann N, Kuhn M, Piosczyk H, Feige B, Baglioni C, Spiegelhalder K, Frase L, Riemann D, Sterr A, Nissen C (2014) The reorganisation of memory during sleep. Sleep Med Rev pii:S1087-0792. CrossRef Medline

Laniado-Laborín R (2010) Smoking cessation intervention: an evidencebased approach. Postgrad Med 122:74-82. CrossRef Medline

Li W, Moallem I, Paller KA, Gottfried JA (2007) Subliminal smells can guide social preferences. Psychol Sci 18:1044-1049. CrossRef Medline

Marshall L, Mölle M, Hallschmid M, Born J (2004) Transcranial direct current stimulation during sleep improves declarative memory. J Neurosci 24:9985-9992. CrossRef Medline

Mascetti L, Muto V, Matarazzo L, Foret A, Ziegler E, Albouy G, Sterpenich V, Schmidt C, Degueldre C, Leclercq Y, Phillips C, Luxen A, Vandewalle G, Vogels R, Maquet P, Balteau E (2013) The impact of visual perceptual learning on sleep and local slow-wave initiation. J Neurosci 33:33233331. CrossRef Medline

Mednick SC, McDevitt EA, Walsh JK, Wamsley E, Paulus M, Kanady JC, Drummond SP (2013) The critical role of sleep spindles in hippocampaldependent memory: a pharmacology study. J Neurosci 33:4494-4504. CrossRef Medline

Mölle M, Marshall L, Gais S, Born J (2004) Learning increases human electroencephalographic coherence during subsequent slow sleep oscillations. Proc Natl Acad Sci U S A 101:13963-13968. CrossRef Medline

Murakami M, Kashiwadani H, Kirino Y, Mori K (2005) State-dependent sensory gating in olfactory cortex. Neuron 46:285-296. CrossRef Medline

Murray EA (2007) The amygdala, reward and emotion. Trends Cogn Sci 11:489-497. CrossRef Medline

Nir Y, Tononi G (2010) Dreaming and the brain: from phenomenology to neurophysiology. Trends Cogn Sci 14:88-100. CrossRef Medline

Nishida M, Walker MP (2007) Daytime naps, motor memory consolidation and regionally specific sleep spindles. PLoS One 2:e341. CrossRef Medline

O'Doherty JP (2004) Reward representations and reward-related learning in the human brain: insights from neuroimaging. Curr Opin Neurobiol 14:769-776. CrossRef Medline

Oudiette D, Antony JW, Creery JD, Paller KA (2013) The role of memory reactivation during wakefulness and sleep in determining which memories endure. J Neurosci 33:6672-6678. CrossRef Medline

Pagliardini S, Greer JJ, Funk GD, Dickson CT (2012) State-dependent modulation of breathing in urethane-anesthetized rats. J Neurosci 32:1125911270. CrossRef Medline

Patrick DL, Cheadle A, Thompson DC, Diehr P, Koepsell T, Kinne S (1994) The validity of self-reported smoking: a review and meta-analysis. Am J Public Health 84:1086-1093. CrossRef Medline

Payne JD, Stickgold R, Swanberg K, Kensinger EA (2008) Sleep preferen- tially enhances memory for emotional components of scenes. Psychol Sci 19:781-788. CrossRef Medline

Peigneux P, Laureys S, Fuchs S, Collette F, Perrin F, Reggers J, Phillips C, Degueldre C, Del Fiore G, Aerts J, Luxen A, Maquet P (2004) Are spatial memories strengthened in the human hippocampus during slow wave sleep? Neuron 44:535-545. CrossRef Medline

Pickens CL, Airavaara M, Theberge F, Fanous S, Hope BT, Shaham Y (2011) Neurobiology of the incubation of drug craving. Trends Neurosci 34:411420. CrossRef Medline

Pierce RC, Kumaresan V (2006) The mesolimbic dopamine system: the final common pathway for the reinforcing effect of drugs of abuse? Neurosci Biobehav Rev 30:215-238. CrossRef Medline

Plailly J, Howard JD, Gitelman DR, Gottfried JA (2008) Attention to odor modulates thalamocortical connectivity in the human brain. J Neurosci 28:5257-5267. CrossRef Medline

Plihal W, Born J (1999) Effects of early and late nocturnal sleep on priming and spatial memory. Psychophysiology 36:571-582. CrossRef Medline

Pollock JD, Koustova E, Hoffman A, Shurtleff D, Volkow ND (2009) Treatments for nicotine addiction should be a top priority. Lancet 374:513514. CrossRef Medline

Price JL (1990) Olfactory system. In: The human nervous system (Paxinos G, ed), pp 979-998. San Diego: Academic.

Rasch B, Büchel C, Gais S, Born J (2007) Odor cues during slow-wave sleep prompt declarative memory consolidation. Science 315:1426-1429. CrossRef Medline

Reber AS, Allen R, Reber PJ (1999) Implicit versus explicit learning. In: The nature of cognition (Sternberg J, ed) pp 475-513. Cambridge, MA: MIT.

Reber PJ (2013) The neural basis of implicit learning and memory: a review of neuropsychological and neuroimaging research. Neuropsychologia 51: 2026-2042. CrossRef Medline

Reber PJ, Squire LR (1998) Encapsulation of implicit and explicit memory in sequence learning. J Cogn Neurosci 10:248-263. CrossRef Medline

Robertson EM, Pascual-Leone A, Press DZ (2004) Awareness modifies the skill-learning benefits of sleep. Curr Biol 14:208-212. CrossRef Medline

Sayette MA, Parrott DJ (1999) Effects of olfactory stimuli on urge reduction in smokers. Exp Clin Psychopharmacol 7:151-159. CrossRef Medline

Schabus M, Gruber G, Parapatics S, Sauter C, Klösch G, Anderer P, Klimesch W, Saletu B, Zeitlhofer J (2004) Sleep spindles and their significance for declarative memory consolidation. Sleep 27:1479-1485. Medline

Schlam TR, Baker TB (2013) Interventions for tobacco smoking. Annu Rev Clin Psychol 9:675-702. CrossRef Medline

Sela L, Sobel N (2010) Human olfaction: a constant state of changeblindness. Exp Brain Res 205:13-29. CrossRef Medline

Sela L, Sacher Y, Serfaty C, Yeshurun Y, Soroker N, Sobel N (2009) Spared and impaired olfactory abilities after thalamic lesions. J Neurosci 29: 12059-12069. CrossRef Medline

Shiffman S, Brockwell SE, Pillitteri JL, Gitchell JG (2008) Use of smokingcessation treatments in the United States. Am J Prev Med 34:102-111. CrossRef Medline

Spoormaker VI, Czisch M, Holsboer F (2013) REM sleep, hippocampus, and memory processing: insights from functional neuroimaging studies. Behav Brain Sci 36:629-630; discussion 634-659. Medline

Stead LF, Lancaster T (2012) Combined pharmacotherapy and behavioural interventions for smoking cessation. Cochrane Database Syst Rev 10: CD008286. CrossRef Medline

Stevenson RJ (2009) Phenomenal and access consciousness in olfaction. Conscious Cogn 18:1004-1017. CrossRef Medline

Stevenson RJ, Boakes RA, Wilson JP (2000) Resistance to extinction of conditioned odor perceptions: evaluative conditioning is not unique. J Exp Psychol Learn Mem Cogn 26:423-440. CrossRef Medline

Stevenson RJ, Case TI, Boakes RA (2005) Implicit and explicit tests of odor memory reveal different outcomes following interference. Learn Motiv 36:353-373. CrossRef

Stickgold R, Walker MP (2013) Sleep-dependent memory triage: evolving generalization through selective processing. Nat Neurosci 16:139-145. CrossRef Medline

Stuck BA, Stieber K, Frey S, Freiburg C, Hörmann K, Maurer JT, Hummel T (2007) Arousal responses to olfactory or trigeminal stimulation during sleep. Sleep 30:506-510. Medline 
Tamminen J, Lambon Ralph MA, Lewis PA (2013) The role of sleep spindles and slow-wave activity in integrating new information in semantic memory. J Neurosci 33:15376-15381. CrossRef Medline

Thiessen GJ (1978) Disturbance of sleep by noise. J Acoust Soc Am 64:216 222. CrossRef Medline

Volkow ND, Wang GJ, Telang F, Fowler JS, Logan J, Childress AR, Jayne M, Ma Y, Wong C (2006) Cocaine cues and dopamine in dorsal striatum: mechanism of craving in cocaine addiction. J Neurosci 26:6583-6588. CrossRef Medline

Wagner U, Hallschmid M, Rasch B, Born J (2006) Brief sleep after learning keeps emotional memories alive for years. Biol Psychiatry 60:788-790. CrossRef Medline

Walker MP, Stickgold R (2006) Sleep, memory, and plasticity. Annu Rev Psychol 57:139-166. CrossRef Medline

Wang Z, Faith M, Patterson F, Tang K, Kerrin K, Wileyto EP, Detre JA, Lerman C (2007) Neural substrates of abstinence-induced cigarette cravings in chronic smokers. J Neurosci 27:14035-14040. CrossRef Medline

Willingham DB, Goedert-Eschmann K (1999) The relation between implicit and explicit learning: evidence for parallel development. Psychol Sci 10:531-534. CrossRef

Wilson DA, Yan X (2010) Sleep-like states modulate functional connectivity in the rat olfactory system. J Neurophysiol 104:3231-3239. CrossRef Medline

Wise RA (1996) Neurobiology of addiction. Curr Opin Neurobiol 6:243251. CrossRef Medline

Won WY, Lee CU, Chae JH, Kim JJ, Lee C, Kim DJ (2014) Changes of plasma adiponectin levels after smoking cessation. Psychiatry Investig 11:173-178. CrossRef Medline

Yeomans MR, Mobini S (2006) Hunger alters the expression of acquired hedonic but not sensory qualities of food-paired odors in humans. J Exp Psychol Anim Behav Process 32:460-466. CrossRef Medline 